\title{
I.UMIBUNG
}

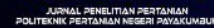

\section{KAJIAN FENOLOGI BUNGA DAN UJI RESEPTIVITAS STIGMA SERTA MORFOLOGI POLEN ANGGREK KALAJENGKING (Arachnis flosaeris ) DI MAGUWOHARJO, SLEMAN}

\author{
Lora Yudistira ${ }^{1}$, Tantri Swandari*2, Titin Setyorini ${ }^{2}$ \\ ${ }^{1}$ Alumni Program Studi Agroteknologi, Fakultas Pertanian Institut Pertanian STIPER, Yogyakarta \\ ${ }^{2}$ Staf Pengajar Program Studi Agroteknologi, Fakultas Pertanian Institut Pertanian STIPER, \\ Yogyakarta \\ *e-mail: tantri14swandari@instiperjogja.ac.id
}

Diterima : 02 Maret 2020

Disetujui : 25 Agustus 2020

Diterbitkan : 31 Agustus 2020

\begin{abstract}
ABSTRAK
Anggrek merupakan tanaman hias yang memiliki nilai ekonomis tinggi dan banyak dibudidayakan dalam skala besar. Penelitian ini bertujuan untuk mengetahui fenologi bunga dan uji reseptivitas stigma serta morfologi polen anggrek Kalajengking (Arachnis flosaeris). Adapun yang menjadi latar belakang penelitian ini adalah sebagai salah satu upaya untuk mengetahui waktu persilangan atau penyerbukan yang tepat bagi tanaman anggrek Kalajengking. Penelitian ini dilakukan di KP2 Institut Pertanian STIPER Yogyakarta, Maguwoharjo, Kabupaten Sleman. Penelitian ini menggunakan metode percobaan yang disusun dalam rancangan acak lengkap (RAL) satu faktor yaitu fase stadium bunga dari mulai anthesis hingga gugur (hari) dengan unit percobaan sebanyak 20 tanaman. Data yang diperoleh selama pengamatan berupa data kualitatif dan kuantitatif. Data kualitatif disajikan dalam bentuk deskriptif komparatif dengan foto untuk menunjukkan hasil pengamatan fenologi bunga berdasarkan tingkat kesegaran bunga. Data kuantitatif dari parameter jumlah gelembung oksigen pada stigma reseptif dan jumlah morfologi polen dianalisis dengan menggunakan Microsoft Excel. Hasil penelitian menunjukkan bahwa bunga anggrek Kalajengking yang telah anthesis dapat bertahan selama rentang waktu 21 hari setelah itu apabila bunga tidak mengalami penyerbukan maka akan layu, mengering dan gugur. Waktu bertahannya bunga berlangsung cukup lama, sehingga tahap optimal reseptivitas stigma anggrek Kalajengking terjadi pada saat bunga di stadium $\mathrm{H}+12$ setelah anthesis. Dari data hasil penelitian didapatkan unit morfologi polen amorf lebih banyak dibandingkan dengan unit morfologi polen tetramorf.
\end{abstract}

Kata kunci: Anggrek Kalajengking; Anthesis; Fenologi; Stigma; Polen.

\section{ABSTRACT}

Orchids are ornamental plants that has high economic value and widely cultivated on a large scale. The aim of this research was to determine phenology of flower and stigma reseptivities test, and pollen morphology of scorpion orchid (Arachnis flosaeris). The background of this research was to determine the exact time of crossing or pollination for the scorpion orchid. This research was conducted at KP2 Institute of Agriculture STIPER Yogyakarta, Maguwoharjo, Sleman Regency. This study used an experimental method arranged in a completely randomized design 


\section{I.UMIBUNG}

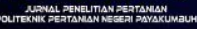

(CRD) of one factor, namely the stage of interest from anthesis to fall (days) with a total of 20 plant experimental units. Data obtained during observation in the form of qualitative and quantitative data. Qualitative data is presented in a comparative descriptive form with photographs to show the results of observations of flowering phenology based on the level of freshness of interest. Quantitative data from the parameters of the number of oxygen bubbles on receptive stigma and the amount of pollen morphology were analyzed using Microsoft Excel. The results showed that the scorpion orchid anthesis can survive for a span of 21 days after that if the flowers do not experience pollination it will wither, dry out and fall. The survival time of the flower lasts quite a long time, so that the optimal stage of scorpion orchid stigma receptivity occurs when the flower is at stage $H+12$ after anthesis. From the research data it was found that the morphological units of amorphous pollen were more numerous than the morphology of the tetramorf pollen units.

Keywords: scorpion orchid; anthesis; phenology; stigma; pollen

\section{PENDAHULUAN}

Indonesia terkenal dengan negara yang kaya akan fauna dan floranya di antaranya tumbuhan anggrek. Anggrek adalah tumbuhan Orchidacea, famili ini diperkirakan 5.000 spesies tersebar di Indonesia (Sutiyoso dan Sarwono, 2002). Anggrek merupakan salah satu tanaman hias yang memiliki nilai ekonomis tinggi sehingga banyak dibudidayakan dalam skala besar.

Banyak upaya yang dilakukan untuk menghasilkan bibit anggrek yang unggul. Salah satu upaya yang dilakukan yaitu dengan dilakukannya persilangan. Anggrek hibrida hasil persilangan biasanya lebih banyak diminati oleh masyarakat dibandingkan anggrek spesies dikarenakan anggrek hibrida memiliki warna, bentuk dan ukuran bunga yang lebih beragam dan bervariasi (Clemants, 2004). Proses hibridisasi yang tepat sangat tergantung pada sifat kematangan bunga selama perkembangannya. Sifat kematangan bunga tersebut antara lain, kapan polen memiliki viabilitas maksimum, kapan stigma mencapai masa reseptif dan siap menampung polen dalam proses penyerbukan. Pada beberapa jenis tumbuhan lain, seperti Azadiracta indica, Averhoa carombala, Durio zibethinus, kematangan stigma dan polen terjadi dalam waktu yang berbeda, yaitu polen lebih dahulu mencapai viabilitas sementara stigma belum mencapai tahap matang (Soepadmo, 1989).

Dengan demikian perlu diketahui fenologi dari perbungaan untuk dapat menentukan waktu kematangan bunga yang tepat. Fenologi merupakan kajian mengenai tahap perkembangan tumbuhan yang terjadi secara periodik dan berlangsungnya dipengaruhi oleh faktor-faktor lingkungan (Fewless, 2006). Fenologi perbungaan merupakan proses awal dari perkembangbiakan suatu tumbuhan dan waktu perbungaan 


\section{I.UMIBUNG}

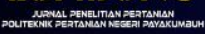

dari kuncup hingga layu pada tumbuhan anggrek berbeda-beda (Tabla dan Vargas, 2004). Salah satu upaya untuk mengetahui waktu penyerbukan atau persilangan yang tepat bagi tanaman anggrek Kalajengking (Arachnis flosaeris) yaitu salah satunya dengan menentukan reseptivitas stigma. Sejauh ini belum ada penelitian tentang kajian fenologi perbungaan dan uji reseptivitas stigma serta morfologi polen anggrek Kalajengking, sehingga penelitian ini perlu dilakukan.

\section{METODE PENELITIAN}

Penelitian dilaksanakan pada bulan Februari - April 2019 di KP2 dan Laboratorium Sentral, Institut Pertanian Stiper Yogyakarta. Alat yang digunakan dalam penelitian antara lain alat tulis, timbangan analitik, pipet, kaca preparat dan mikroskop. Bahan yang digunakan adalah larutan Hidrogen Peroxida $\left(\mathrm{H}_{2} \mathrm{O}_{2}\right) 3 \%$, sukrosa, $\mathrm{H}_{3} \mathrm{BO} 3, \mathrm{Ca}\left(\mathrm{NO}_{3}\right)_{2}$, $\mathrm{MgSO}_{4} .7 \mathrm{H}_{2} \mathrm{O}, \mathrm{KNO} 3$, akuades dan larutan safranin. Penelitian ini menggunakan metode percobaan yang disusun dalam rancangan acak lengkap (RAL) satu faktor yaitu fase stadium bunga dari mulai anthesis hingga gugur (hari) dengan unit percobaan sebanyak 20 tanaman.

Pelaksanaan penelitian meliputi 1) Pengamatan fenologi bunga, dilakukan pada individu yang mempunyai bagian bunga atau batang yang sehat dan memiliki kuncup bunga yang kecil (Dafni, 1992). Pada pengamatan perkembangan bunga, bunga diberi label lalu dicatat perkembangan bunga dari anthesis hingga layu disertai dokumentasi, 2) Uji Reseptivitas Stigma, pengamatan kemampuan reseptivitas stigma dalam menerima polen dengan dilakukan uji reseptif stigma dengan menggunakan larutan hidrogen peroksida (Dafni, 1992). Stigma diambil dengan pinset kemudian dimasukan ke dalam larutan hidrogen peroksida 3\%. Stigma dinyatakan reseptif jika menunjukan reaksi positif terhadap larutan tersebut yang ditandai dengan terbentuk dan terlepasnya gelembunggelembung udara dari permukaan stigma akibat adanya enzim peroksidase. Lama pengujian yang dilakukan pada tahap uji reseptivitas stigma yaitu selama 2 dan 5 menit, 3) Morfologi Polen, tahapan yang dilakukan dalam melakukan penelitian morfologi polen, yaitu: a) menyiapkan media polen mengikuti media perkecambahan polen yang digunakan oleh Brewbaker dan Kwack (1964) yang selanjutnya disebut sebagai media BK. Media BK terdiri dari 1, 2 M sukrosa; 0,200 gram $\mathrm{H}_{3} \mathrm{BO} 3$; 0,417 gram $\mathrm{Ca}\left(\mathrm{NO}_{3}\right) 2 ; 0,217$ $\mathrm{MgSO} 4.7 \mathrm{H}_{2} \mathrm{O}$; dan 0,101 gram $\mathrm{KNO}_{3}$ dalam $1000 \mathrm{ml}$ aquades (Anonim, 1997), b) membuat larutan campuran $1 \mathrm{ml}$ sukrosa dan $3 \mathrm{ml}$ garam mineral kemudian rendam polen 


\section{I.UMIBUNG}

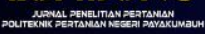

selama 30 menit dalam campuran kedua larutan tersebut sebanyak $1 \mathrm{ml}$ dan setelah itu polen dihancurkan menggunakan pinset, c) meneteskan cairan polen yang telah dihancurkan pada kaca preparat kemudian tambahkan 1 tetes larutan safranin untuk diamati menggunakan mikroskop, d) pengamatan dilakukan sebanyak 3 kali ulangan dengan tiga bidang pandang berbeda dengan menggunkan mikroskop. Uji ini dilakukan sesuai prosedur pada uji pendahuluan, sampel yang digunakan adalah polen anggrek yang diambil dari stadium perkembangan bunga mekar hingga gugur $(\mathrm{H}$ hingga $\mathrm{H}+21)$, untuk melihat morfologi polen berdasarkan usia bunga mekar.

Analisis Data, data yang diperoleh selama pengamatan berupa data kualitatif dan kuantitatif. Data kualitatif disajikan dalam bentuk deskriptif komparatif dengan foto untuk menunjukkan hasil pengamatan fenologi perbungaan berdasarkan tingkat kesegaran bunga. Data kuantitatif dari parameter jumlah gelembung oksigen pada stigma reseptif dan jumlah morfologi polen dianalisis dengan menggunakan Microsoft Excel.

\section{HASIL DAN PEMBAHASAN}

Anthesis pada bunga anggrek Kalajengking ditandai dengan terlihatnya bagianbagian bunga seperti tiga helai sepal, dua helai petal dan satu helai labellum. Selain itu polen yang sudah matang pada anggrek Kalajengking yang telah anthesis akan berwarna kuning tua serta stigma sudah mengeluarkan banyak lendir.

Berdasarkan penelitian pendahuluan yang telah dilaksanakan pada bulan Januari 2019 diketahui bunga anggrek Kalajengking yang telah anthesis hanya dapat bertahan selama rentang waktu 21 hari setelah itu apabila bunga tidak mengalami penyerbukan maka akan mengering, layu dan gugur. Bunga anggrek Kalajengking mulai layu pada stadium $\mathrm{H}+18$ dan $\mathrm{H}+21$. Layunya bunga anggrek Kalajengking ini dapat dilihat pada bagian sepal bunga yang mulai mengering dan berubah warna menjadi kecokelatan. Apabila dibandingkan dengan lama perbungaan anggrek jenis lain, perbungaan anggrek Kalajengking setelah anthesis tergolong lebih lama jika dibandingkan dengan anggrek Merpati. Pada bunga anggrek Merpati yang telah anthesis hanya dapat bertahan selama satu hari setelah itu bunga akan kembali menguncup dan layu (Nita, 2015).

Namun pada beberapa kesempatan ditemukan bunga anggrek Kalajengking yang layu dengan cepat hal ini tentunya dipengaruhi oleh berbagai macam faktor seperti suhu, kondisi tanaman serta hama dan penyakit yang menyerang tanaman anggrek Kalajengking itu sendiri. Seperti yang diketahui bahwa anggrek Kalajengking cocok tumbuh pada daerah 


\section{I.UMIBUNG}

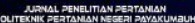

dataran tinggi dengan intensitas penyinaran matahari penuh. Sedangkan daerah tempat penelitian dilakukan merupakan daerah dataran rendah dimana kelembabannya cenderung lebih rendah dibandingkan dengan daerah dataran tinggi. Sehingga hal tesebut mempengaruhi kondisi tanaman dimana tanaman menjadi mudah kering seperti terbakar dikarenakan suhu panas terik selama pengamatan berlangsung.

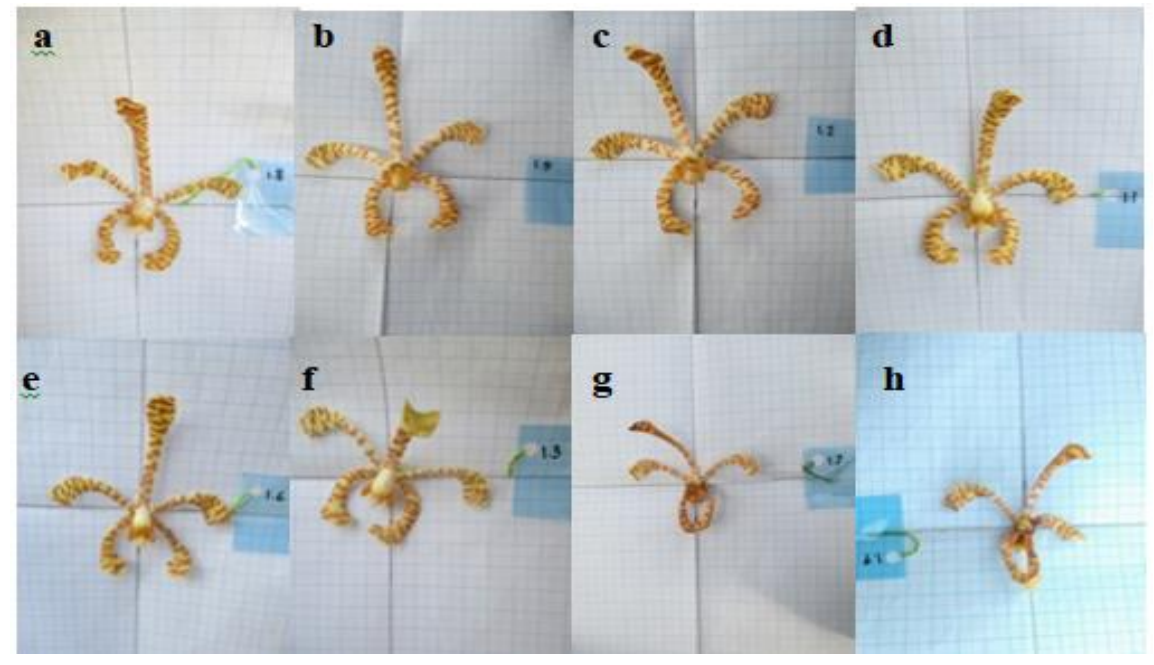

Gambar 1. Fenologi bunga anggrek Arachnis flosaeris mulai dari anthesis hingga gugur. (a) bunga anthesis atau mekar, (b) bunga stadium $\mathrm{H}+3$, (c) bunga stadium $\mathrm{H}+6$, (d) bunga stadium $\mathrm{H}+9$, (e) bunga stadium $\mathrm{H}+12$, (f) bunga stadium $\mathrm{H}+15$, (g) bunga layu pada stadium $\mathrm{H}+18$, dan (h) bunga stadium $\mathrm{H}+21$ atau gugur.

Faktor lain yang menyebabkan layunya bunga anggrek Kalajengking dengan cepat adalah hama. Beberapa hama yang umumnya berasosiasi dengan tanaman anggrek yaitu, semut, belalang, siput, trips, ulat dan kepik. Terkhusus selama penelitian berlangsung tanaman anggrek Kalajengking diserang hama siput yang dalam semalam bisa menghabiskan daun ataupun bunga dan membuat daun atau bunga tersebut gugur pada keesokan harinya. Oleh karena itu perlu dilakukannya pengendalian dengan cara meletakan iris-irisan mentimun disekitar tanaman anggrek.

Tabel 1 menunjukan jumlah gelembung oksigen yang dihasilkan stigma anggrek Kalajengking pada stadium $\mathrm{H}+12$ dengan lama pengujian 2 dan 3 menit memiliki hasil yang paling tinggi. 


\section{I.UMIBUNG}

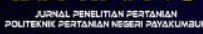

Tabel 1. Data Pengamatan Reseptivitas Stigma

\begin{tabular}{clcr}
\multirow{2}{*}{ No. } & Umur Bunga & \multicolumn{2}{c}{ Lama Pengujian } \\
\cline { 3 - 4 } 1. & $\mathrm{H} 0$ & 2 Menit & 5 Menit \\
2. & $\mathrm{H}+3$ & 334,5 & 1038,5 \\
3. & $\mathrm{H}+6$ & 461,3 & 938,7 \\
4. & $\mathrm{H}+9$ & 412,9 & 825,6 \\
5. & $\mathrm{H}+12$ & 413,7 & 641,3 \\
6. & $\mathrm{H}+15$ & $\mathbf{4 8 3 , 5}$ & $\mathbf{1 2 3 9 , 2}$ \\
7. & $\mathrm{H}+18$ & 362,3 & 736,4 \\
8. & $\mathrm{H}+21$ & 219,6 & 395,6 \\
& & 180,1 & 423,5 \\
\hline
\end{tabular}

Keterangan: Angka yang diperoleh merupakan hasil rerata dari lama pengujian stigma selama 2 dan 3 menit.

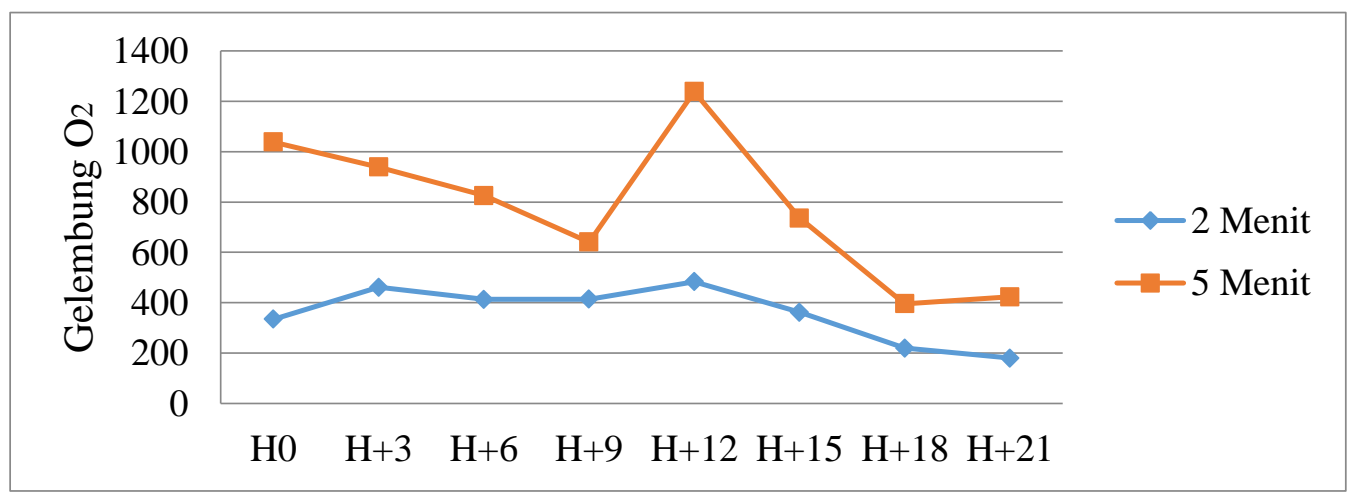

Gambar 2. Pengamatan Reseptivitas Stigma

Pada pengamatan reseptivitas stigma, secara visual stigma reseptif ditandai dengan adanya sekresi cairan berupa lendir di permukaan stigma. Berdasarkan uji dengan Hidrogen Peroxida $\left(\mathrm{H}_{2} \mathrm{O}_{2}\right)$ pada bunga anthesis, stigma sudah reseptif. Hal ini ditandai dengan munculnya gelembung oksigen dari permukaan stigma. Uji pada bunga anggrek Kalajengking berdasarkan yang telah anthesis dari $\mathrm{H}+0$ sampai $\mathrm{H}+21$, semua stigma sudah reseptif untuk menerima polen (Tabel 1). Berdasarkan hasil tersebut, dapat dikatakan bahwa anggrek Kalajengking memiliki kecendrungan untuk polinasi sendiri (autogami), karena reseptifnya stigma berlangsung cukup lama, demikian tahap optimal reseptivitas stigma anggrek Kalajengking sendiri terjadi pada saat bunga di stadium $\mathrm{H}+12$ setelah anthesis.

Hal yang mempengaruhi reseptivitas stigma yaitu aktivitas enzim esterase pada stigma yang sudah terlihat pada bunga yang telah mekar. Namun, pada awal anthesis aktifitas enzim esterase hanya terlihat sebagian kecil permukaan stigma atau belum merata. Pada bunga mekar penuh, aktifitas enzim esterase terdapat pada seluruh permukaan 


\section{I.UMIBUNC}

\section{(1)}

stigma. Menurut Lord dan Kohorn (1986) adanya aktifitas enzim esterase pada permukaan stigma menunjukkan stigma mulai efektif yaitu siap menerima polen.

Dari hasil penelitian juga menunjukan bahwa setelah berada pada tahap optimal, reseptivitas stigma kemudian cenderung mengalami penurunan. Hal ini kemungkinan terjadi karena adanya penurunan aktivitas enzim esterase dimana seperti yang telah dibahas sebelumnya bahwa memasuki stadium $\mathrm{H}+18$ sampai $\mathrm{H}+21$ bunga sudah mengalami perubahan termasuk berkurangnya enzim esterase yang terdapat pada stigma anggrek Kalajengking (Gambar 3).

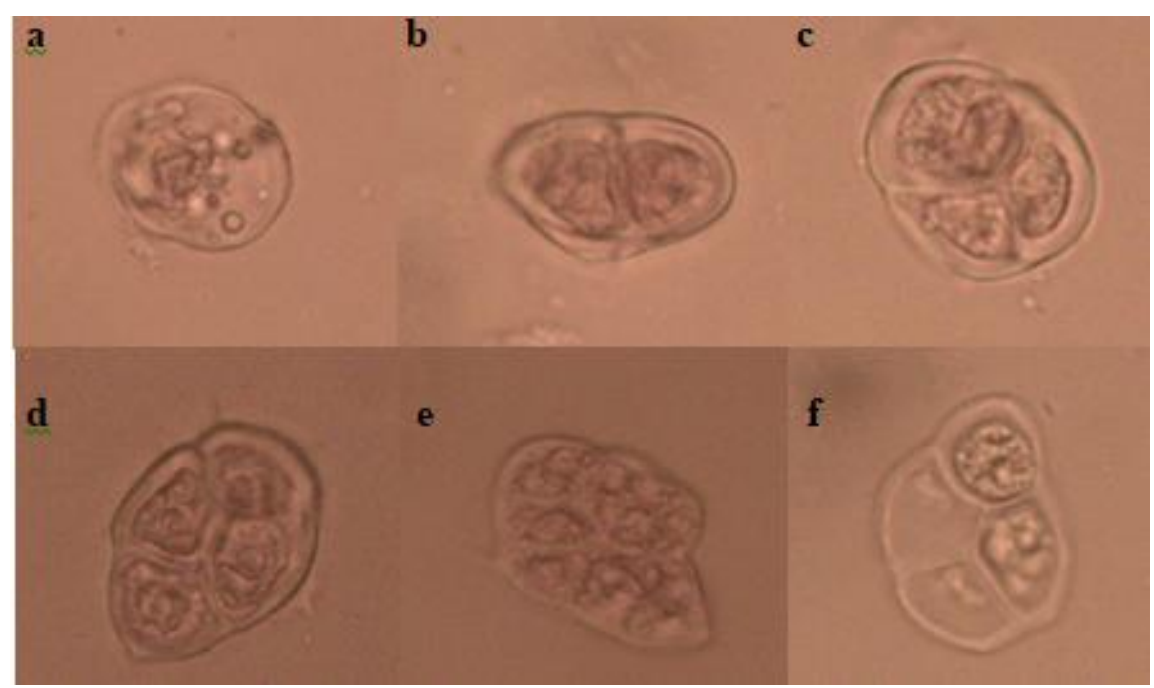

Gambar 3. Klasifikasi morfologi polen Arachnis flosaeris. (a) Mono, (b) Di, (c) Tri, (d) Tetra, (e dan f) Amorf.

Tabel 2. Keseluruhan Persentase Morfologi Polen Arachnis flosaeris

\begin{tabular}{ccccccccc}
\hline \multirow{2}{*}{ Morfologi Polen } & \multicolumn{7}{c}{ Persentase $(\%)$} \\
\cline { 2 - 8 } Mono & 1,3 & 0 & 0,9 & 3,1 & 2,4 & 0,7 & 0 & 0,5 \\
Di & 4 & 2,1 & 3,6 & 1,6 & 4,8 & 1,4 & 3,9 & 5,8 \\
Tri & 20 & 16,8 & 12,4 & 16,7 & 19,3 & 15,9 & 21,8 & 18,4 \\
Tetra & $\mathbf{5 0 , 7}$ & 35,8 & 39,1 & 38,1 & $\mathbf{4 9 , 4}$ & 34,5 & 30,7 & 28,0 \\
Amorf & 24 & $\mathbf{4 5 , 3}$ & $\mathbf{4 4}$ & $\mathbf{4 0 , 5}$ & 24,1 & $\mathbf{4 7 , 5}$ & $\mathbf{4 3 , 6}$ & $\mathbf{4 7 , 3}$ \\
\hline
\end{tabular}

Keterangan : Angka yang disajikan merupakan hasil dari persentase morfologi polen Arachnis flosaeris berdasarkan stadiumnya.

Kemudian pada pengamatan morfologi polen anggrek Kalajengking diketahui bahwa rata-rata persentase tertinggi unit morfologi yang ditemui adalah polen tetramorf dan amorf berdasarkan stadiumnya. Dari data keseluruhan hasil penelitian didapatkan unit morfologi polen amorf lebih banyak dibandingkan dengan unit morfologi polen tetramorf. 


\section{I.UMIBUNG}

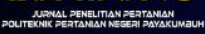

Unit morfologi polen tetramorf paling banyak ditemukan pada bunga stadium $\mathrm{H}+0$ dan $\mathrm{H}+12$ selain dari kedua stadium tersebut, unit morfologi polennya adalah amorf. Sedangkan jumlah unit morfologi polen amorf paling banyak ditemukan pada bunga anggrek Kalajengking stadium $\mathrm{H}+15$. Perbedaan hasil ini dikarenakan adanya ketidakstabilan sampel selama penelitian dilaksanakan. Hal ini disebabkan karena sampel yang digunakan berasal dari bunga pada tanaman yang berbeda-beda.

Hal lain yang perlu diketahui bahwa polen mempunyai struktur dinding kompleks yang terdiri dari dua lapisan dasar, yaitu intine (inti) dan exine (eksin). Inti atau lapisan tengah langsung berhubungan dengan sitoplasma, yaitu bagian dalam polen yang akan hilang apabila polen tersebut mati. Sedangkan eksin merupakan bagian luar butiran dengan permukaan berupa struktur yang beraneka ragam.

Bentuk butir polen ini juga terkait dengan tipe aperturanya yaitu, suatu area tipis pada eksin yang berhubungan dengan perkecambahan polen (Suedy, 2012). Polen dengan unit morfologi amorf umumnya merupakan sekumpulan polen yang saling bertumpuk sehingga tidak bisa dikategorikan karena bentuknya cenderung tidak jelas. Selain itu, bisa juga polen dengan unit morfologi amorf merupakan polen yang bagian intinya sudah hilang atau mati.

\section{KESIMPULAN}

Bunga anggrek kalajengking memiliki lama perbungaan 21 hari, terhitung dari mulai anthesis hingga gugur. Reseptivitas stigma yang optimal ditunjukan pada bunga stadium $\mathrm{H}+12$ setelah anthesis. Unit morfologi polen amorf paling banyak ditemukan pada semua bunga berdasarkan stadiumnya

\section{REFERENSI}

Anonim. 1997. Polen Germination with Fast Plants. University of Wisconsin. Madison.

Brewbaker, J.L. and B.H. Kwack. 1964. The calcium ion and substances influencing pollen growth. In H. F. Linskens (Ed.). Pollen Physiology and Fertilization. North-Holland Publishing Company. Amsterdam.

Clemants, S. 2004. The Best Orchid for Indoors. Brooklyn Botanic Garden, Inc. Washington.

Dafni, A. 1992. Pollinations Ecology A Practical Approach. Oxford University Press. New York.

Fewless, G. 2006. Phenology. University of Wisconsin. Green Bay.

Lord, E.M. and L.U. Kohorn. 1986. Gynoecial Development, Pollination, and The Path of Pollen Tube Growth in The Tepary Bean, Phaseolus acustifolius. Amer. J. Bot. 73 (1): 70-78. 


\section{I.UMIBUNG}

Nita, S.R. 2015. Kajian Fenologi Perbungaan Anggrek Merpati (Dendrobium curmenatum Sw.) di Limau Manis Padang, Sumatera Barat. J.Bio.UA. 4 (3) : 188-192.

Soepadmo, E. 1989. Contribution of Reproductive Biological Studies Towards the Conservation and Development of Malaysian Plant Genetic Resources. dalam A.H. zakri (ed.) Genetic Resources of Underutilized Plants in Malaysia. Proceeding of The National Workshop on Plant Genetic Resources. Subang Jaya, Malaysia 23 Nov. 1988. Malaysia National Committee on Plant Genetic Resources. Malaysia. p: 1-41.

Suedy, S.W.A. 2012. Paleorekonstruksi Vegetasi Dan Lingkungan Menggunakan Fosil Polen Dan Spora Pada Formasi Tapak Cekungan Banyumas Kala Plio-Plistosen. Sekolah Pascasarjana Institut Pertanian Bogor. Bogor.

Sutiyoso, Y. dan B. Sarwono. 2002. Merawat Anggrek. Cetakan 2. Penebar Swadaya. Jakarta.

Tabla, V.P. dan C.F. Vargas. 2004. Phenology and phenotypic natural selection on the flowering time of a deceit-pollinated tropical orchid, Myrmecophila christinae. Annals of Botany, 94(2): 243- 250. 